\title{
Effect of Age, Ethnicity, and Head Injury on the Association between APOE Genotypes and Alzheimer's Disease
}

\author{
MING-XIN TANG, ${ }^{a, d}$ GLADYS MAESTRE, ${ }^{d, g}$ \\ WEI-YANN TSAI, ${ }^{c}$ XIN-HUA LIU, ${ }^{a}$ LIN FENG, ${ }^{g}$ \\ WAI-YEE CHUNG, ${ }^{g}$ MICHAEL CHUN, ${ }^{e}$ \\ PETER SCHOFIELD, ${ }^{e}$ YAAKOV STERN, ${ }^{a, c, e, q}$ \\ BENJAMIN TYCKO, ${ }^{d, s}$ AND RICHARD MAYEUX ${ }^{a, b, d, e, f}$ \\ ${ }^{a}$ Gertrude H. Sergievsky Center \\ ${ }^{b}$ Division of Epidemiology \\ and \\ ${ }^{c}$ Division of Biostatistics \\ School of Public Health \\ ${ }^{d}$ Taub Center for Alzheimer's Disease Research \\ 'Department of Neurology \\ ${ }^{f}$ Department of Psychiatry \\ ${ }^{8}$ Department of Pathology \\ Columbia University \\ College of Physicians and Surgeons \\ New York, New York 10032
}

\section{INTRODUCTION}

The apolipoprotein E (APOE)- $\epsilon 4$ allele is neither necessary nor sufficient to cause Alzheimer's disease (AD) because it develops in the absence of APOE $\in 4,1,2$ and some persons escape the disease despite having an APOE $\epsilon 4$ allele. $^{3}$ Although the presence of the $\epsilon 4$ allele of the APOE gene has been consistently associated with an increased risk of $\mathrm{AD},{ }^{2,4-20}$ it is apparent that the degree of risk may be modified by age, ${ }^{10,21}$ gender, ${ }^{22}$ ethnic group, ${ }^{2}$ certain risk factors, ${ }^{23}$ and possibly other genes. ${ }^{24}$

Roses et al. ${ }^{11,21}$ proposed that APOE genotypes have a direct influence on the age at onset of disease. In both familial and sporadic $A D$, an earlier age at onset among APOE $\epsilon 4$ homozygous and APOE $\epsilon 4$ heterozygous cases than among those cases with other APOE genotypes. Thus, it is possible that

\footnotetext{
${ }^{h}$ Address for correspondence: Richard Mayeux, G. H. Sergievsky Center, 630 West 168th Street, Columbia University, New York, NY 10032; Fax: 212-305-2518; E-mail: rpm2@columbia.edu.
} 
APOE genotypes strongly influence age at onset and that certain factors, both genetic and nongenetic, modify this effect by shifting the distribution curves.

In this review we will discuss demographic and putative risk factors that may modify (enhance or diminish) the association between APOE genotypes and $\mathrm{AD}$.

\section{METHODS}

\section{Subjects and Setting}

All information was obtained from $\mathrm{AD}$ cases and controls residing in the same community and have been described in several earlier publications. ${ }^{2.7,23,25}$ Two different ascertainment methods were used to identify the study populations. Cases and controls were identified as part of a comprehensive community-based registry of all dementias in northern Manhattan and a random sample of Medicare recipients as previously described. ${ }^{2.7}$ The Columbia University institutional review board reviewed and approved this project. All individuals provided written informed consent. Both groups of cases and controls were followed over a four-year period.

\section{Diagnosis of Alzheimer's Disease}

The diagnosis of $\mathrm{AD}$ was based on standard research criteria. ${ }^{26,27} \mathrm{We}$ previously reported the development of our diagnostic method and its relationship to the cultural and educational demographics of this community. ${ }^{28,29}$ The reliability and consistency of these assessments have also been described. ${ }^{30}$

\section{Age at Onset}

Because we used a cross-sectional design with follow-up, a large number of cases identified with prevalent AD were included. We did not attempt to use an estimate of the age at onset because of the difficulty in substantiating this type of information. To improve validity, we used a more conservative method and censored the age at onset (left censored). ${ }^{31-33}$ We have recently described the method of estimate relativing risks using this type of approach. ${ }^{25}$

\section{Ethnic Group}

Ethnic group was classified by self-report using the format of the 1990 United States Census Bureau. ${ }^{34}$ This allows each person to identify him or herself as belonging to a particular racial or ethnic group. Each person is then asked whether or not he or she is of "Hispanic" origin. 


\section{APOE Genotyping}

Genomic DNA was amplified by polymerase chain reaction (PCR) and subjected to Cfol restriction analysis using APOE primers and conditions modified from those as previously described by Hixson and Vernier. ${ }^{35}$ Genotypes were determined without knowledge of patient or control status.

\section{Risk Factors and Family History}

A structured interview was used to inquire about behaviors such as smoking, alcohol use, coffee consumption, dietary habits, antiperspirant use, insecticide exposure, exposure to household solvents, head injury, athletic activity now and in the past, previous hip or wrist fractures, and use of exogenous hormones. For several of the items, we attempted to determine the "dose" of the exposure with follow-up questions. A family history interview for $\mathrm{AD}$ and other neurological disorders in first-degree relatives (parents and full siblings) was obtained. The interviews were given in English or Spanish according to the preference of the patient's informant or the control. The reliability of this interview has been reported. ${ }^{36}$

\section{Data Analysis}

APOE allele frequencies were determined by counting alleles and calculating sample proportions. To compare across ethnic groups, APOE allele frequencies were calculated using all data from all controls and a $10 \%$ random sample of the total number of cases within each ethnic group to create a representative population. For comparison of cases and controls within and across ethnic groups, APOE allele frequencies were calculated for all subjects.

We used an iterative method to obtain the nonparametric maximum likelihood estimate of age at onset from the "self-consistent equation," 25,31 and then used a parametric approach to develop a proportional hazards regression model to estimate the relative risks of $\mathrm{AD}$ by APOE genotype. ${ }^{25}$

Univariate and multivariate relative risks for $A D$ associated with various APOE genotypes were derived from the proportional hazards model and both univariate, and multivariate odds ratios for $A D$ associated with APOE 64 were also calculated from logistic regression, ${ }^{23}$ adjusting for age, education, and ethnic group.

\section{RESULTS}

\section{Demographics}

Data were available for 276 cases and 405 healthy elderly unrelated controls. Cases and controls differed by gender (75\% $\mathrm{AD}$ women vs. $66 \%$ control women, $\chi^{2}=6.5, p<0.01$ ). In all ethnic groups combined, cases 
TABLE 1. Demographics and APOE Allele Frequency among Patients with Alzheimer's Disease and Controls by Ethnic Groups

\begin{tabular}{|c|c|c|c|c|c|c|}
\hline Ethnic Groups & $n$ & Age & Education & APOE- $\epsilon 3$ & APOE- $\epsilon 4$ & APOE- $\epsilon 2$ \\
\hline \multicolumn{7}{|l|}{ African-American } \\
\hline $\mathrm{AD}$ & 106 & $78(7.6)$ & $7.4(4.0)$ & 0.66 & 0.23 & 0.11 \\
\hline Controls & 154 & $74(5.8)^{a}$ & $9.4(3.8)^{a}$ & 0.73 & 0.20 & 0.07 \\
\hline \multicolumn{7}{|l|}{ Caucasian } \\
\hline $\mathrm{AD}$ & 59 & $71(9.1)$ & $13.4(4.2)$ & 0.70 & 0.27 & 0.03 \\
\hline Controls & 112 & $72(8.5)$ & $12.3(4.0)^{a}$ & 0.84 & 0.09 & 0.07 \\
\hline \multicolumn{7}{|l|}{ Hispanic } \\
\hline$A D$ & 140 & $77(8.3)$ & $4.8(3.7)$ & 0.74 & 0.19 & 0.07 \\
\hline Controls & 219 & $73(6.1)^{a}$ & $7.0(4.3)^{a}$ & 0.83 & 0.10 & 0.07 \\
\hline
\end{tabular}

NOTE: Allelic frequencies differed significantly between cases and controls within and across ethnic groups. See text for explanation.

${ }^{a}$ Denotes significant difference within each stratum $(p<0.05)$.

were older (AD $76.4 \pm$ standard deviation [SD] 9.2 [range 46 to 96]) than controls (72.9 \pm SD 6.7 [range 46 to 93], $p<0.05$ ). African-Americans and Hispanics were older and less well educated than Caucasians (TABLE 1). Cases also had less education (AD $7.4 \pm 5.0$ vs. controls $8.8 \pm 4.5, p<$ 0.05 ) than controls.

\section{APOE Allele Frequencies}

The APOE allele frequencies also differed significantly in the three ethnic groups $\left(\chi^{2}=24.6,4 \mathrm{df}, p<0.0001\right)$. The frequency of APOE $€ 4$ among African-Americans was higher with increasing age. Among African-Americans in the lowest quartile of age (below age 68) to the highest (age 77 and older) the APOE $€ 4$ frequency was greater than $20 \%$, whereas among Caucasians the frequency decreased from $16 \%$ to $7.5 \%$. APOE allele frequencies did not differ by gender.

Among AD cases, the distribution of APOE alleles also differed across ethnic groups $\left(\chi^{2}=15.1, \mathrm{df} 4, p=0.01\right)$, with higher frequencies of APOE $\epsilon 4$ in Caucasians (29\%) than in African-Americans (24.7\%) or Hispanics $(18.6 \%)$ and with higher frequencies of APOE $\epsilon 2$ in African-Americans $(12.1 \%)$ than in the other two ethnic groups (Caucasians $2.7 \%$, Hispanics $6.6 \%$; see TABLE 1 ).

\section{Relative Risk}

Specific APOE genotypes in cases and controls for each ethnic group are found in TABLE 2 . The relative risk (RR) of AD among African-Americans homozygous for the APOE $\epsilon 4$ allele was significantly increased $(R R=3.3$; 
TABLE 2. Relative Risk of Alzheimer's Disease by APOE Genotypes in Cases and Controls by Ethnic Group

\begin{tabular}{lcllll}
\hline \multicolumn{1}{c}{ Ethnic Groups } & $\epsilon 3 / \epsilon 3$ & any $\epsilon 2$ & & any $\epsilon 4$ & \multicolumn{1}{c}{$\epsilon 4 / \epsilon 4$} \\
\hline African-American & & & & \\
$\quad$ Alzheimer's disease & 49 & 19 & 28 & 10 \\
At risk & 126 & 36 & 86 & 12 \\
RR & 1.0 & $1.4 ;(0.8-2.6)^{a}$ & $0.6 ;(0.4-0.9)^{a}$ & $3.3 ;(1.6-6.8)^{a}$ \\
Caucasian & & & & \\
Alzheimer's disease & 30 & 1 & 24 & 4 \\
At risk & 108 & 15 & 44 & 4 \\
RR & 1.0 & $0.3 ;(0.4-2.3)^{a}$ & $3.2 ;(1.8-5.8)^{a}$ & $5.3 ;(1.6-16.1)^{a}$ \\
Hispanic & & & & \\
Alzheimer's disease & 80 & 13 & 38 & 6 \\
At risk & 228 & 43 & 79 & 9 \\
RR & 1.0 & $0.9 ;(0.5-1.8)^{a}$ & $1.5 ;(1.0-2.2)^{a}$ & $2.5 ;(1.1-5.8)^{a}$ \\
\hline
\end{tabular}

NotE: The number in each column represents the number of individuals with that specific genotype.

${ }^{a} 95 \%$ ci.

$95 \%$ c.i. 1.6-6.8) compared with APOE $€ 3 / € 3$ genotypes. The risk associated with APOE $€ 4$ heterozygosity was significantly decreased ( $R R=0.6 ; 95 \%$ c.i. 0.4-0.9). For Caucasians, the relative risks associated with either APOE $\epsilon 4$ homozygosity $(R R=5.3 ; 95 \%$ c.i. $1.6-16.1)$ or heterozygosity $(R R=3.2$; 95\% c.i. 1.8-5.8) were significantly increased compared with APOE $€ 3 / € 3$ genotypes. Among Hispanics, the relative risks were increased for APOE $€ 4$ homozygous individuals ( $R R=2.5 ; 95 \%$ c.i. $1.1-5.8$ ) and in APOE $\in 4$ heterozygous individuals ( $R R=1.595 \%$ c.i. $1.0-2.2$ ) compared with APOE $€ 3 / \epsilon 3$ genotypes. Each analysis was repeated stratifying by gender and by including educational level as a covariate, but the results were identical.

We also examined the protective effect of APOE genotypes with one or more $\epsilon 2$ alleles using APOE $\epsilon 3 / \epsilon 3$ genotypes again as the reference. The risk of disease associated with APOE $€ 2$ was lower among Caucasians $(R R=$ $0.3 ; 95 \%$ c.i. $0.4-2.3)$, but not African-Americans $(R R=1.4 ; 95 \%$ c.i. 0.8 2.6) or Hispanics $(R R=0.9 ; 95 \%$ c.i. $0.5-1.8)$.

\section{Head Injury}

In a subset of 113 patients with $\mathrm{AD}$ and 123 healthy elderly persons we used a case-control design to examine the joint effects of head injury and APOE genotypes. Thirteen patients (11.5\%) with $\mathrm{AD}$ had a history of head trauma associated with loss of consciousness preceding onset of dementia, while $10(8.1 \%)$ controls reported a similar injury. The odds ratio (OR) for $\mathrm{AD}$ associated with head injury was $1.5(95 \%$ c.i. $0.5-3.5, p=0.5)$. Using persons with neither a history of head injury nor an APOE $\epsilon 4$ allele as the 
reference group, we estimated the $\mathrm{OR}$ for $\mathrm{AD}$ associated with both a history of traumatic head injury and the presence of at least one APOE $\epsilon 4$ allele $(\mathrm{OR}=10.5 ; 95 \%$ c.i. $1.3-87.8)$, traumatic head injury alone $(\mathrm{OR}=1.0 ; 95 \%$ c.i. $0.3-2.9$ ), and the presence of $A P O E \epsilon 4$ alone $(O R=2.0 ; 95 \%$ c.i. 1.1 3.5) adjusting for age by logistic regression. The OR for the joint effect of head injury and APOE $€ 4$ exceeded that expected from the independent effects of both risk factors, suggesting a synergistic relationship.

\section{DISCUSSION}

We examined the effect of APOE genotypes on the relative risk of $A D$ among three distinct ethnic groups residing in New York City. The APOE $\epsilon 4 / € 4$ genotype was associated with a higher relative risk of $A D$ in all ethnic groups. Among Caucasians and Hispanics, APOE $€ 4$ heterozygosity was also associated with a significantly higher relative risk of $\mathrm{AD}$ compared with APOE genotypes without an $€ 4$ allele. Among African-Americans, however, the increased risk was restricted to persons with the APOE $\in 4 / \in 4$ genotype; APOE $\epsilon 4$ heterozygotes had a significantly lower relative risk of AD. Stratification by gender, family history of $\mathrm{AD}$, or educational level did not change the association between APOE $\epsilon 4$ and $A D$ in any ethnic group. There was only minimal evidence of a reduced risk for AD associated with APOE $\epsilon 2$ genotypes in Caucasians, and there was no decrease in risk for AfricanAmericans or Hispanics.

A strong association between APOE $\epsilon 4$ and AD has been previously reported among African-Americans in Indiana. ${ }^{20}$ The APOE $\epsilon 4$ frequency among controls $(0.12)$ was lower than that reported here. Differences in APOE allele frequencies by ethnic group are well established, ${ }^{37-42}$ and there are regional differences among African populations. ${ }^{40-42}$

The APOE $\epsilon 4$ allele frequency among the African-Americans in this study did not decline with age in contrast to the trend noted among Caucasians in the United States and Europe. ${ }^{43-45}$ The decline in the frequency of APOE $\epsilon 4$ with age in Caucasians has been attributed to mortality from heart disease, ${ }^{44,46-49}$ because variations in the APOE locus affect cholesterol concentrations. ${ }^{37,45}$ APOE $€ 4$ does not consistently predict cholesterol concentrations in persons of African origin..$^{40,41.50}$ Thus it is possible that the APOE protein may be modified by other factors in African-Americans.

The data concerning head injury in this population suggest a synergistic relationship between an environmental risk factor and APOE $\in 4$. In the absence of APOE $€ 4$, the risk of AD associated with head injury was not elevated; thus, our results indicate that the effect of head injury on AD risk may be restricted to persons either homozygous or heterozygous for APOE $\epsilon 4$. The findings are most consistent with a model in which an environmental risk factor has no effect alone, yet it exacerbates the effect of genetic susceptibility. The findings further integrate the roles of $\beta$-amyloid and APOE $\epsilon 4$, suggesting that the APOE $€ 4$ gene increases susceptibility to $A D$, which can be exacerbated by the effects of an environmental stimulus such as traumatic head injury. 
Population-based prospective studies that address the demographic factors of age, ethnic group, gender, and socio-economic status should provide information concerning the risk of $A D$ associated with APOE $€ 4$ in these circumstances. Similarly, previous investigations of risk factors should be repeated to include APOE genotypes in order to appreciate the relationship between genetic and environmental factors in this disease.

\section{SUMMARY}

The association between apolipoprotein E (APOE)- $\epsilon 4$ and Alzheimer's disease has been confirmed worldwide. We and others have observed a diminished association in the very old and among African-Americans compared to Caucasians and Hispanics in New York. In this review we describe a new method we developed to compare relative risks by APOE genotypes in an expanded cohort of cases and controls from three ethnic groups in a New York City community and discuss the association as between APOE $\epsilon 4$ and Alzheimer's disease as modified by head injury.

Compared to persons with APOE $\epsilon 3 / \epsilon 3$ genotypes, relative risk (RR) for Alzheimer's disease associated with APOE $€ 4$ homozygosity was similar across ethnic groups (African-American $R R=3.3 ; 95 \%$ c.i. 1.6-6.8; Caucasian $\mathrm{RR}=5.3 ; 1.6-16.0$; Hispanic $\mathrm{RR}=2.5 ; 1.1-5.8$ ). The risk was also increased for APOE $€ 4$ heterozygous Caucasians $(R R=3.2 ; 1.8-5.8)$ and Hispanics (RR 1.5; 1.0-2.2) but not African-Americans ( $R R=0.6 ; 0.4-0.9)$. Risk of $\mathrm{AD}$ was not significantly diminished for individuals in any group with APOE $\epsilon 2 / \epsilon 2$ or $-\epsilon 2 / \epsilon 3$ genotypes. A 10 -fold increase in the risk of Alzheimer's disease was associated with both APOE $€ 4$ and a history of traumatic head injury, compared to a twofold increase in risk with APOE $\epsilon 4$ alone. Head injury in the absence of an APOE $€ 4$ allele did not increase risk.

These results imply that in Alzheimer's disease genotypic risk associated with APOE may be influenced by age, ethnicity, and certain enviromental factors.

\section{ACKNOWLEDGMENTS}

The authors wish to thank Marcel Kempowski, Adria Gonzales, John Shinin, Maria Gonzales, Harold Brown, and Jean Denaro for their technical assistance in this project. We also acknowledge the efforts of Drs. Barry Gurland, David Wilder, and Rafael Lantigua from the Center for Geriatrics and Gerontology at Columbia University in the design and conduct of the registry and Medicare survey.

The work was supported by federal Grants AG07232, AG10963, AG08702, and RR00645, the Charles S. Robertson Memorial Gift for Alzheimer's Disease Research from the Banbury Fund. 


\section{REFERENCES}

1. Lannfelt, L., L. Lilius, M. Nastase, M. Vittanen, L. Fratiglioni, G. Eggersten \& L. BERgLAND. 1994. Lack of association between apolipoprotein $E$ allele epsilon 4 and sporadic Alzheimer's disease. Neurosci. Lett. 169: 175-178.

2. Maestre, G., R. Ottman, Y. Stern, B. Gurland, M. Chun, M.-X. Tang, M. Shelanski, B. Tyско \& R. MAYEuX. 1995. Apolipoprotein-E and Alzheimer's disease: Ethnic variation in genotypic risks. Ann. Neurol. 37: 254-259.

3. Polvikoski, T., R. Sulkava, M. Haltia, K. Kainulainen, A. Vuorio, A. Verkkoniemi, L. Ninisto, P. Halonen \& K. Kontula. 1995. Apolipoprotien E, dementia and cortical depostion of $\beta$-amyloid protein. N. Engl. J. Med. 333: $1242-1247$.

4. Brogaonkar, D. S., L. C. Schmidit, S. E. Martin, M. D. Kanzer, L. Edel.sohn, J. GRowdon \& L. A. Farrer. 1993. Linkage of late-onset Alzheimer's disease with apolipoprotein-E type 4 on chromosome 19. Lancet 342: 625 .

5. Corder, E. H., A. M. Saunders, W. J. Strittmatter, D. E. Schmechel, P. C. Gaskel, G. W. Small, A. D. Roses, J. L. Haines \& M. Pericak-Vance. 1993. Gene dose of apolipoprotein-E type 4 allele and the risk of Alzheimer's disease in late onset families. Science 261: $921-923$.

6. Corder, E. H., A. M. Saunder, N. J. Risch, W. J. Strittmatter, D. E. Schmechel, P. C. Gaskel \& J. B. Rimmler. 1994. Apolipoprotein E type 2 allele decreases the risk for late onset Alzheimer's disease. Nature Genet. 7: 180-184.

7. Mayeux, R., Y. Stern, R. Ottman, T. K. Tatemichi, M.-X. Tang, G. Maestre, C. Ngai, B. Tycko \& H. Ginsberg. 1993. The apolipoprotein $\epsilon 4$ allele in patients with Alzheimer's disease. Ann. Neurol. 34: 752 754.

8. Noguchi, S., K. Murukami \& N. Yamada. 1993. Apolipoprotein E genotype and Alzheimer's disease. Lancet 342: 737.

9. Payami, H., J. Kaye, L. L. Heston, T. Bird \& G. D. Schellenberg. 1993. ApolipoproteinE genotype and Alzheimer's disease. Lancet 342: 738.

10. Poirier, J., J. Davignon, D. Bouthillier, S. Kogan, P. Bertrand \& S. Gauthier. 1993. Apolipoprotein E polymorphism and Alzheimer's disease. Lancet 342: 697-699.

11. Roses, A. D., W. J. Strittmatter, M. A. Pericak-Vance, E. H. Corder, A. M. SaunDERS \& D. E. SCHMECHEL. 1994. Clinical application of apolipoprotein E genotyping to Alzheimer's disease. Lancet 343: 1564 - I565.

12. Saunders, A. M., W. J. Strittmatter, D. Schmechel, P. H. St. George-Hyslop, M. A. Pericak-Vance, S. H. Joo, B. L. Rosi \& A. D. Roses. 1993. Association of apolipoprotein $\mathrm{E}$ allele e4 with late-onset familial and sporadic Alzheimer's disease. Neurology 43: 1467-1472.

13. Saunders, A. M., K. Schmader, J. C. S. Brietner, M. D. Benson, W. T. Brown, L. GoldFarb, D. Goldgaber \& A. D. Roses. 1993. Apolipoprotein-E $\epsilon 4$ allele distributions in late-onset Alzheimer's disease and in other amyloid-forming diseases. Lancet 342: $710-711$.

14. Strittmatter, W. J., A. M. Saunders, D. Schmechel, M. Pericak-Vance, J. Enghild, G. S. Salvesen \& A. D. Roses. 1993. Apolipoprotein E: High-affinity binding to betaamyloid and increased frequency of type 4 allele in late-onset familial Alzheimer's disease. Proc. Natl. Acad. Sci. 90: 1977-1981.

15. Strittmatter, W. J., K. H. Weisgraber, D. Huang, L. M. Dong, G. S. Salvesen, M. Pericak-Vance, D. Schmechel \& A. D. Roses. 1993. Binding of human apolipoprotein $E$ to $\beta$-A4 peptide: Isoform-specific effects and implications for late-onset Alzheimer's disease. Proc. Natl. Acad. Sci. 90: 8098-8102.

16. Chartier-Hardlin, M.-C., M. Parfitt, S. Legarin, J. Perez-Tur, T. Brousseau, A. Evans, C. BER, et al. 1994. Apolipoprotein E, $\in 4$ allele as a major risk factor for sporadic early and late-onset forms of Alzheimer's disease: Analysis of the 19q13.2 chromosomal region. Human Mol. Gen. 3: 569-574. 
17. Kuusisto, J., K. Koivisto, K. Kervinen, L. Mykkanen, E. L. Helkala, M. Vanhanen \& T. HANNiEN. 1994. Association of apolipoprotein-E phenotypes with late onset Alzheimer's disease: Population based study. Br. Med. J. 309: 636-638.

18. Sorbi, S., B. Nacmias, P. Forleo, S. Latorraca, I. Gobbini, L. Bracco, S. Piacentini \& L. AMADUCCI. 1994. ApoE allele frequencies in Italian sporadic and familial Alzheimer's disease. Neurosci. Lett. 177: 100-102.

19. LidDell, M., J. Williams, A. Bayer, F. Kaiser \& M. Owen. 1994. Confirmation of association between the 4 allele of apolipoprotein $\mathrm{E}$ and Alzheimer's disease. J. Med. Genet. 31: 197-200.

20. Hendrie, H. C., K. S. Hall, S. Hui, F. W. Unverzagt, C. E. Yu, D. K. Lahiri \& A. SAHOTA. 1995. Apolipoprotein-E genotypes and Alzheimer's disease in a community study of elderly African-Americans. Ann. Neurol. 37: 118-120.

21. Roses, A. D. 1995. Apolipoprotein E genotyping in the differential diagnosis, not prediction of Alzheimer's disease. Ann. Neurol. 38: 6-14.

22. Payami, H., K. R. Montee, J. Kaye, E. M. Wusman, T. Bird, C.-E. Yu, L. L. Heston \& G. D. SCHELlenBerg. 1994. Apolipoprotein-E genotype and Alzheimer's disease. JAMA 271: 1316-1317.

23. Mayeux, R., R. Ottman, G. Maestre, C. Ngai, M.-X. Tang, H. Ginsberg, M. Chun, B. TYCKo \& M. S. ShelansKI. 1995. Synergistic effects of traumatic head injury and apolipoprotein- $\epsilon 4$ in patients with Alzheimer's disease. Neurology 45: 555-557.

24. Osuntokun, B. O., A. Sahota, A. O. Ogunniyi, O. Gureje, O. Baileywu, A. Adeyinka \& S. O. OluwOLE. 1995. Lack of an association between apolipoprotein $E \in 4$ and Alzheimer's disease in elderly Nigerians. Ann. Neurol. 38: 463-465.

25. Kamboh, M. I., D. K. Sanghera, R. E. Ferrell \& S. T. DeKosky. 1995. APOE*4associated Alzheimer's disease risk is modified by $\alpha 1$-antichymotrysin polymorphism. Nature Genet. 10: 486-488.

26. Tang, M.-X., G. Maestre, W.-Y. Tsai, X.-H. Liu, L. Feng, W.-Y. Chung, M. Chun, P. SChofield, Y. STERN, B. Tycko \& R. MAYEUX. 1996. Relative risk of Alzheimer's disease and age-at-onset based on APOE genotypes among elderly African-Americans, Caucasians and Hispanics in New York City. Am. J. Hum. Genet. 58: 554-574.

27. American Psychiatric Association. 1987. Diagnostic and Statistical Manual of Mental Disorders, Third Edition-Revised. American Psychiatric Association. Washington, DC. pp. 205-224.

28. McKhann, G., D. Drachman, M. Folstein, R. Katzman, D. Price \& E. M. Stadlan. 1984. Clinical diagnosis of Alzheimer's disease: Report of NINCDS-ADRDA Work Group under the auspices of the Department of Health and Human Services Task Force on Alzheimer's Disease. Neurology 34: 939-944.

29. Pittman, J., H. Andrews, T. Tatemichi, B. Link, E. Struening, Y. Stern \& R. Mayeux. 1992. Diagnosis of dementia in a heterogenous population: A comparison of paradigmbased diagnosis and physician's diagnosis. Arch. Neurol. 49: 461-467.

30. Stern, Y., H. Andrews, J. Pittman, M. Sano, T. Tatemichi, R. Lantigua \& R. Mayeux. 1992. Diagnosis of dementia in a heterogenous population: Development of a neuropsychological paradigm and quantified correction for education. Arch. Neurol. 49: 453-460.

31. Schofield, P. W., M.-X. Tang, K. Marder, K. Bell, G. Dooneief, R. Lantigua, D. WILDER \& R. MAYEUX. 1995. Consistency of clinical diagnosis in a community-based longitudinal study of dementia and Alzheimer's disease. Neurology 45: 2159-2164.

32. TURNBULL, B. W. 1974. Nonparametric estimation of survivorship function with doubly censored data. J. Am. Stat. Assoc. 69: 169-174.

33. Cupples, L. A., N. J. Risch, L. A. Farrer \& R. H. MYers. 1991. Estimation of age at onset with missing information of onset. Am. J. Hum. Genet. 49: 76-87.

34. TANG, M.-X., W.-Y. Tsai, K. Marder \& R. MaYeuX. 1995. Linear rank tests for doubly censored data. Stat. Med. 14: 2555-2563.

35. Census of Population and Housing. 1991. 1990: Summary Tape File 1 Technical Documentation Prepared by Bureau of Census. Census Bureau. Washington, DC. 
36. Hixson, J. \& D. Vernier. 1991. Restriction isotyping of human apolipoprotein E by gene amplification and cleavage with HhAI. J. Lipid Res. 31: 545-548.

37. Mayeux, R., R. Ottman, M.-X. Tang, L. Noboa-Bauza, K. Marder, B. Gurland \& Y. STERN. 1993. Genetic susceptibility and head injury as risk factors for Alzheimer's disease among community-dwelling elderly persons and their first-degree relatives. Ann. Neurol. 33: 494-501.

38. Davignon, J., R. E. Gregg \& C. F. Sing. 1988. Apolipoprotein E polymorphism and atherosclerosis. Arteriosclerosis 8: $1-21$.

39. Hallman, D. M., E. Boerwinkle, N. Saha, C. Sandholzer, H. J. Menzel, A. Csazar \& G. UTERMANN. 1991. The apolipoprotein E polymorphism: A comparison of allele frequencies and effects in nine populations. Am. J. Hum. Genet. 49: 338-349.

40. Камвон, M. I., B. Sepehrnia \& R. E. Ferrell. 1989. Genetic studies of human apolipoproteins. VI. Common polymorphism of apolipoprotein E in blacks. Dis. Markers 7: 49-55.

41. Sepehrnia, B., M. I. Kamboh, L. L. Adams-Campbell, C. H. Bunker, M. Nwankwo, P. P. Majumder \& R. E. Ferrell. 1989. Genetic studies of human apolipoproteins. $X$. The effect of the apolipoprotein $E$ polymorphism on quantitative levels of lipoproteins in Nigerian blacks. Am. J. Hum. Genet. 45: 586-591.

42. Sandholzer, C., R. Delport, H. Vermaak \& G. Utermann. 1995. High frequency of the apo epsilon 4 allele in Khoi San from South Africa. Hum. Genet. 95: 46-48.

43. Zekraoui, L., G. Lucotte \& A. Raisonnier. 1995. Apolipoprotein E genotypes in Africa: Alleleic frequencies and ethnic groups. Paper presented at the Ibsen Foundation Meeting. Paris, France, May 29.

44. Schachter, F., L. Faure-Delanef, F. Guenot, H. Rouger, P. Froguel, L. LesueurGinot \& D. COHEN. 1994. Genetic associations with human longevity at the APOE and ACE loci. Nature Genet. 6: 29-32.

45. Kervinen, K., M. J. Savolainen, J. Salokannel, A. Hynninen, J. Heikrinen, C. EhnhOLM, M. J. KoIstinen \& Y. A. Kesaniemi. 1994. Apolipoprotein E and B polymorphics-longevity factors assessed in nonagenarians. Atherosclerosis 105: 89-95.

46. Lounija, J., H. E. Miettinen, K. Kontula, M. J. Tikmanen, T. A. Miettinen \& R. S. TILVIS. 1994. Aging and genetic variation of plasma apolipoprotiens. Relative loss of the apolipoprotein E4 phenotype in centenarians. Arterioscler. Thromb. 14: 1084- 1089.

47. Eichner, J. E., L. H. Kuller, T. J. Orchard, G. A. Grandits, L. M. McCallum, R. E. FerRell \& J. D. Neaton. 1993. Relation of apolipoprotein E phenotype to myocardial infarction and mortality from coronary artery disease. Am. J. Cardiol. 71: 160-165.

48. Wilson, P. W., R. H. Myers, M. G. Larson, J. M. Ordovas, P. A. Wolf \& E. J. SCHAEFER. 1994. Apolipoprotein E alleles, dyslipidemia, and coronary heart disease. The Framingham Offspring Study. JAMA 272: 1666-1671.

49. LuC, G., J. M. BARD \& D. ARveILER. 1994. Impact of apolipoprotein E polymorphism on lipoproteins and risk of myocardial infarction. The ECTIM Study. Arterioscler. Thromb. 14: 1412-1419.

50. Stengard, J. H., K. E. Zerba, J. Pekranen, C. Ehnholm, A. Nissinen \& C. F. Sing. 1995. Apolipoprotein $E$ polymorphis predicts death from coronary heart disease in a longitudinal study of elderly Finnish men. Circulation 91: 265-269.

51. Garjra, B., J. K. Candlish, N. Saha, J. W. MaK \& J. S. Tay. 1994. Effect of apolipoprotein $\mathrm{E}$ variants on plasma lipids and apolipoproteins in the Orang Asli ('aborigines') of Malaysia. Human Heredity 44: 209-213. 